\title{
PENGENALAN LITERASI KEUANGAN DAN PERSONAL BRANDING DI ERA DIGITAL BAGI GENERASI Z DI SMK PGRI 1 KEDONDONG
}

\author{
Dhiona Ayu Nani ${ }^{1}$, Larasati Ahluwalia ${ }^{2}$, Dian Novita ${ }^{3}$ \\ Universitas Teknokrat Indonesia ${ }^{\mathbf{1}, \mathbf{2} 3}$
}

Email : dhiona.a@teknokrat.ac.id ${ }^{1}$, larasati.ahluwalia@teknokrat.ac.id ${ }^{2}$,diannovita@teknokrat.ac.id ${ }^{3}$

\begin{tabular}{lll}
\hline Received: (27 Juli 2021) & Accepted: (30 Agustus 2021) & Published : (15 September 2021) \\
\hline
\end{tabular}

\begin{abstract}
Research conducted by Kredivo and Katadata in 2020, generation $Z$ and Millennials contributed $85 \%$ of total transactions. Furthermore, the government is currently focusing on recovering the national economy, which has fallen due to the ongoing Covid-19 pandemic. Generation Z, which is expected to become a demographic bonus for the workforce in the next few years, should be equipped with financial literacy and personal branding in order to survive and compete with the environment. This Community Service is carried out with the aim of providing an understanding of financial literacy and personal branding. As previously discussed, Generation $Z$ needs to be equipped with financial literacy so that later they can be financially independent. In addition, students can develop themselves through personal branding that utilizes digital business platforms.
\end{abstract}

Keywords: Generation Z, Millennials, National Economy, Financial Literacy, Personal Branding

\begin{abstract}
Abstrak
Riset yang dilakukan oleh Kredivo dan Katadata tahun 2020, generasi Z dan Milenial berkontribusi sebesar $85 \%$ dari total transaksi. Lebih lanjut, pemerintah saat ini tengah fokus dalam pemulihan ekonomi nasional yang turun karena pandemi Covid-19 yang belum mereda. Generasi Z yang diharapkan menjadi bonus demografi tenaga kerja beberapa tahun ke depan, sebaiknya dibekali dengan literasi keuangan dan bisnis digital agar mampu bertahan dan bersaing dengan lingkungannya. Pengabdian Kepada Masyarakat ini dilakukan dengan tujuan untuk memberikan pemahaman mengenai literasi keuangan dan personal branding. Seperti yang telah dibahas sebelumnya, Generasi $\mathrm{Z}$ perlu dibekali dengan literasi keuangan agar nantinya mereka bisa mandiri secara finansial. Selain itu, siswa dapat mengembangkan dirinya melalui personal branding yang memanfaatkan platform bisnis digital.
\end{abstract}

Kata Kunci: Generasi Z, Milenial, Ekonomi Nasional, Literasi Keuangan, Personal Branding

\section{To cite this article:}

Nani, D. A., Ahluwalia, L., \& Novita, D. (2021). Pengenalan Literasi Keuangan dan Personal Branding di Era Digital Bagi Generasi Z di SMK PGRI 1 Kedondong. Journal of Technology and Social for Community Service (JTSCS), Vol(2), 43-47.

\section{PENDAHULUAN}

Kehidupan dalam era modern memudahkan manusia untuk melakukan semua aktivitasnya, mulai dari belanja kebutuhan harian, membeli makanan, sampai melakukan investasi pada Lembaga keuangan. Kemudahan ini disebabkan oleh peningkatan teknologi daring(Setiawansyah et al., 2020; Sulistiani et al., 2021; Surahman et al., 2020). Riset yang dilakukan oleh Kredivo dan Katadata tahun 2020, generasi Z dan Milenial berkontribusi sebesar $85 \%$ dari total transaksi. Lebih lanjut, pemerintah saat ini tengah fokus dalam pemulihan ekonomi nasional yang turun karena pandemi Covid-19 yang belum mereda. Generasi Z yang diharapkan menjadi bonus demografi tenaga kerja beberapa tahun kedepan, sebaiknya dibekali dengan literasi keuangan dan personal branding agar mampu bertahan dan bersaing dengan lingkungannya. Literasi keuangan terkait instrumen investasi dan pengelolaan keuangan pribadi baiknya dikuasai sejak dari bangku sekolah menengah. Sementara itu, personal branding baiknya dikuasai agar siswa mampu memiliki pemahaman mengenai bagaimana mengenalkan diri mereka kepada publik. SMK PGRI 1 Kedondong yang berlokasi di Kecamatan Kedondong, Kabupaten Pesawaran memiliki potensi untuk berkembang. SMK PGRI 1 Kedondong berfokus pada program 
administasi perkantoran dan multimedia, sehingga mereka penting untuk dibekali pemahaman dasar terkait literasi keuangan dan personal branding. SMK PGRI 1 Kedondong memiliki 11 rombongan belajar, dengan jabaran 150 siswa multimedia dan 194 siswa perkantoran, dan telah menggunakan kurikulum K-13 Rev. Sayangnya, SMK PGRI 1 Kedondong belum memiliki laboratorium untuk peningkatan pengetahuan digital siswa. Pengabdian Kepada Masyarakat (PKM) ini dilakukan dengan tujuan untuk memberikan pemahaman mengenai literasi keuangan dan personal branding.

Seiring berjalannya waktu, saat ini setiap individu bertanggung jawab atas keuangan pribadinya(Ahdan \& Sari, 2020). Terlebih, saat ini telah berkembang Financial Technology (fintech) yang memudahkan orang untuk melakukan pembayaran hingga menentukan investasi kuangan yang cocok dengan dirinya(Suryono et al., 2019), sehingga penting untuk memiliki pengetahuan finansial dan sejauh mana pengetahuan finansial ini mempengaruhi pengambilan keputusan (Lusardi, 2019). Salah satu bentuk literasi keuangan adalah investasi. Menurut Jogiyanto (2017), investasi merupakan penundaan konsumsi saat ini untuk kepuasan di masa mendatang. Investasi terbagi menjadi investasi langsung dan tidak langsung. Investasi langsung dilakukan dengan membeli aktiva keuangan yang tidak dapat diperjual-belikan (Jogiyanto, 2017). Aktiva ini bisa berupa tabungan atau sertifikat deposito. Selanjutnya, investasi tidak langsung dilakukan dengan membeli surat-surat berharga dari perusahaan yang menjual sahamnya ke publik. Terdapat berbagai jenis investasi yang bisa dicoba untuk Generasi $Z$ tentunya dengan pantauan orang tua. Jenis-jenis investasi ini antara lain deposito, logam mulia, obligasi, dan reksa dana.

Selain memberikan pemahaman tentang literasi keuangan, pengabdian kepada masyarakat ini juga dilakukan untuk memberikan pemahaman mengenai personal branding. Mempromosikan diri sendiri merupakan bagian dari personal branding. Hal ini berkaitan dengan bagaimana kita ingin orang lain mengenali pencapaian kita, apa yang telah kita lakukan. Seseorang melakukan personal branding untuk meningkatkan visibilitas dan kesadaran terhadap orang lain, meningkatkan kunjungan pada sosial media, hingga meningkatkan penjualan. Deckers dan Lacy (2011) menjelaskan bahwa personal branding adalah bagaimana kita mempromosikan diri kita sehingga kita bisa mendapatkan banyak peluang. Jika hal ini dilakukan oleh siswa, tentu akan memberikan banyak sekali manfaat karena siswa dapat mempersiapkan dirinya untuk memasuki dunia kerja dengan membekali dirinya dengan personal branding.

\section{METODE PELAKSANAAN \\ Tempat dan Waktu}

Pelaksanaan Pengabdian Kepada Masyarakat dilakukan di SMK PGRI 1 Kedondong yang terletak di Kedondong, Kabupaten Pesawaran, Provinsi Lampung. Kegiatan ini dilakukan dengan dua tahapan, di mana tahap pertama dilakukan pada Januari 2021 dan tahap kedua dilakukan pada Mei 2021.

\section{Khalayak Sasaran}

Sasaran dalam kegiatan Pengabdian ini adalah siswa/siswi di SMK PGRI 1 Kedondong.

\section{Metode Pengabdian}

Kegiatan ini dilakukan menggunakan beberapa tahapan sebagai berikut:

1. Analisis Kebutuhan Mitra.

Tahapan yang pertama kali dilakukan adalah dengan menganalisis kebutuhan mitra PKM yaitu SMK PGRI 1 Kedondong. Berdasarkan kunjungan yang dilakukan, diperoleh kebutuhan yaitu pemberian materi mengenai literasi keuangan dan personal branding bagi siswa/siswi SMK PGRI 1 Kedondong.

2. Pemberian angket untuk menguji pemahaman peserta mengenai sosialisasi yang akan diberikan.

Sebelum sosialisasi dilakukan, siswa/siswi SMK PGRI 1 Kedondong diberikan kuesioner untuk menguji pemahaman mereka mengenai sosialisasi yang akan diberikan. Kuesioner diberikan sebelum sosialisasi dilaksanakan (pre-test) dan setelah sosialisasi dilakukan (post-test). Tujuannya adalah untuk mengukur apakah setelah sosialisasi dilakukan terdapat peningkatan pemahaman siswa/siswi mengenai literasi keuangan dan personal branding.

3. Sosialisasi Literasi Keuangan.

Setelah memperoleh kebutuhan mitra, Tim PKM melaksanakan sosialisasi sesuai dengan kebutuhan mitra. Sosialisasi yang pertama adalah pemaparan mengenai literasi keuangan. Pada sosialisasi ini, siswa/siswi 
SMK PGRI 1 Kedondong diberikan pemahaman mengenai pentingnya mengelola keuangan pribadi dan pengenalan instrument investasi.

4. Sosialisasi Personal Branding.

Sosialisasi yang kedua adalah pemberian materi mengenai personal branding. Pada sosialisasi ini siswa/siswi SMK PGRI 1 Kedondong diberikan pemahaman mengenai pentingnya pengembangan diri di era digital. Siswa/siswi juga diarahkan untuk memanfaatkan platform media sosial untuk membentuk pengembangan dirinya sehingga siswa/siswi bisa mendapatkan banyak peluang di masa depan.

\section{HASIL DAN PEMBAHASAN}

Kegiatan PKM ini diawali dengan kunjungan pertama yang dilakukan untuk menganalisis kebutuhan mitra. Kegiatan awal ini dilakukan dengan langsung mengunjungi SMK PGRI 1 Kedondong dan bertemu dengan Kepala Jurusan, yaitu Ibu Meda Soraya. Pada kegiatan ini, Tim mengawali dengan penyampaian maksud dan tujuan melaksanakan kegiatan PKM serta merangkum kebutuhan yang diperlukan oleh siswa/siswi SMK PGRI 1 Kedondong. Setelah dilakukan kunjungan yang pertama, diperoleh permasalahan mitra yaitu minimnya pengetahuan mengenai literasi keuangan dan pengembangan diri di era digital. Berdasarkan analisis permasalahan mitra yang diperoleh, Tim PKM melakukan diskusi untuk mempersiapkan solusi yang bisa ditawarkan atas permasalahan tersebut. Berdasarkan diskusi yang dilakukan Tim PKM, telah disepakati bahwa Tim akan melakukan sosialisasi mengenai literasi keuangan dan pengembangan diri kepada siswa/siswi SMK PGRI 1 Kedondong.

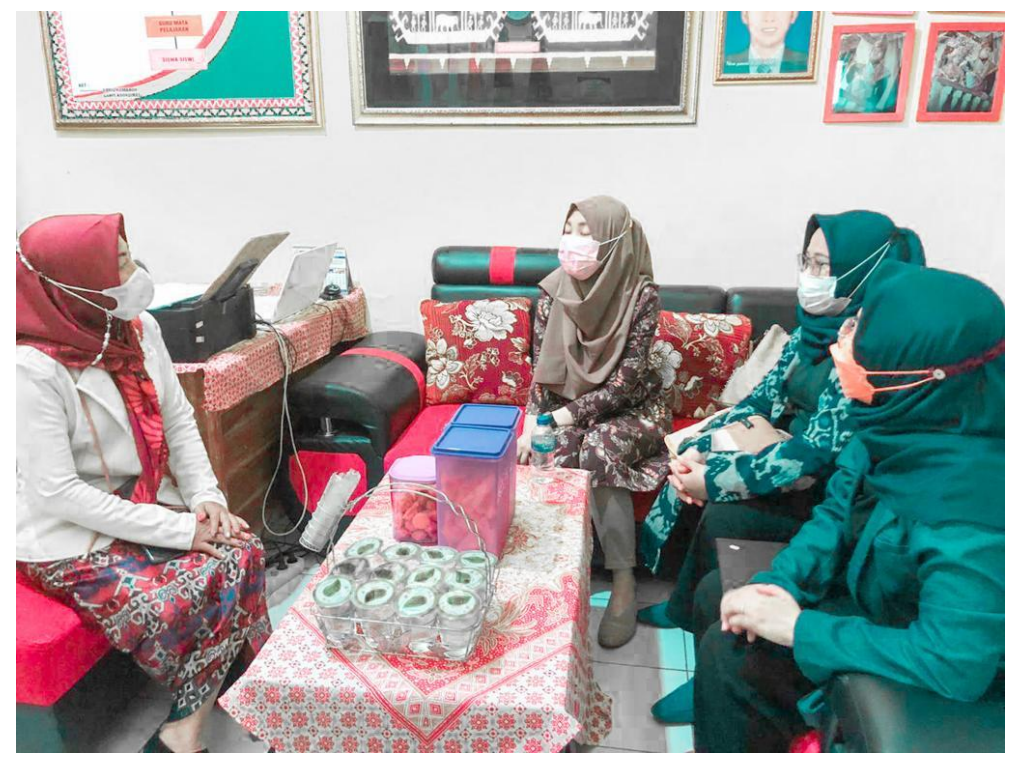

Gambar 1. Pertemuan TIM PKM dengan Kepala Jurusan SMK PGRI 1 Kedondong

Setelah menemukan analisis kebutuhan mitra dan solusi yang dapat ditawarkan oleh Tim PKM kepada siswa/siswi SMK PGRI 1 Kedondong, maka Tim PKM melakukan kunjungan yang kedua untuk memberikan sosialisasi mengenai literasi keuangan dan personal branding. Kegiatan kedua ini diikuti oleh 30 siswa/siswi SMK PGRI 1 Kedondong. Terbatasnya jumlah peserta dikarenakan pandemi Covid-19 yang mengharuskan dilakukannya social distancing ketika pelaksanaan kegiatan. Pada kegiatan kedua ini, materi pertama yaitu mengenai literasi keuangan disampaikan oleh narasumber pertama dari Tim PKM, yaitu Ibu Larasati Ahluwalia. Materi ini disampaikan untuk memberikan pembekalan mengenai pengelolaan keuangan pribadi dan pengenalan investasi bagi siswa/siswi SMK PGRI 1 Kedondong. Pada materi ini, narasumber mengawali dengan memberikan pemahaman mengenai perencanaan keuangan Generasi $\mathrm{Z}$ dan dilanjutkan dengan rekomendasi pengaturan anggaran bulanan yang pas untuk Generasi Z. Materi ditutup dengan pemahaman tentang jenis investasi yang bisa dilakukan untuk Generasi $\mathrm{Z}$ dengan pantauan orang tua. 


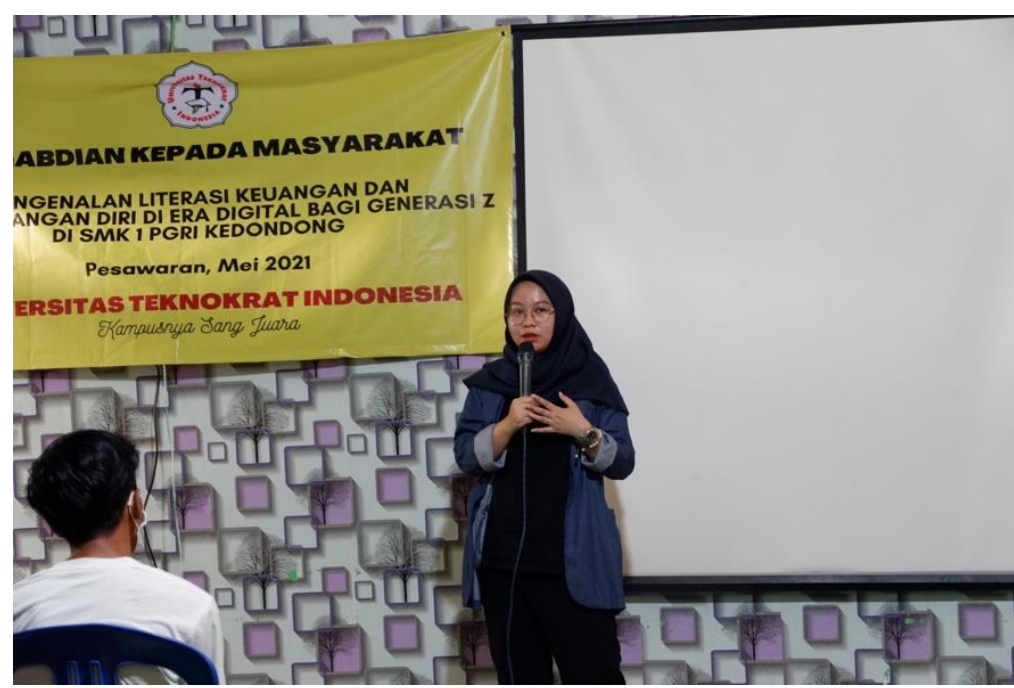

Gambar 2. Penyampaian Materi Mengenai Literasi Keuangan

Materi selanjutnya yang disampaikan adalah mengenai personal branding. Pada materi ini, siswa/siswi SMK PGRI 1 Kedondong diberikan pemahaman mengenai pentingnya membangun personal branding di era digital oleh narasumber kedua yaitu Ibu Dian Novita. Seperti yang diketahui bahwa Sekolah Menengah Kejuruan (SMK) merupakan sekolah yang mempersiapkan lulusannya untuk dapat langsung bekerja, sehingga penting bagi siswa/siswi ini untuk bisa mengenalkan dirinya kepada orang lain dengan memanfaatkan media sosial untuk mendapatkan banyak peluang salah satunya peluang dalam memasuki dunia kerja. Media sosial yang bisa dimanfaatkan oleh siswa/siswi ini antara lain Instagram, Facebook, YouTube, Twitter, dan berbagai media sosial lainnya.

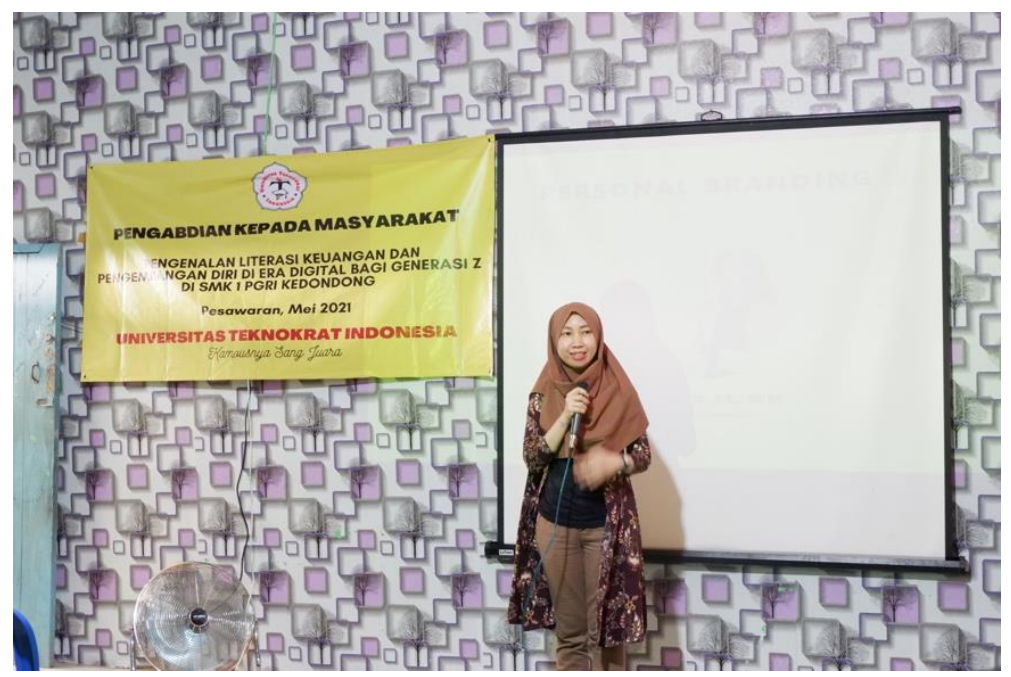

Gambar 3. Penyampaian Materi Mengenai Personal Branding

\section{KESIMPULAN}

Berdasarkan kegiatan yang dilakukan, dapat disimpulkan bahwa siswa/siswi SMK PGRI 1 Kedondong telah memperoleh pemahaman yang baik mengenai literasi keuangan dan personal branding. Sosialisasi yang dilakukan oleh Tim PKM memberikan dampak sosial bagi peserta yang mengikuti kegiatan ini. Dengan pemahaman mengenai literasi keuangan, peserta dapat mengelola keuangan pribadinya dengan baik serta mulai memilih instrumen investasi yang cocok bagi dirinya. Selain itu, pemahaman mengenai personal branding juga 
memberikan manfaat yang besar bagi para peserta kegiatan ini. Dengan pemahaman mengenai personal branding, peserta bisa mulai mengembangkan diri dengan memanfaatkan media sosial sehingga peluang untuk memasuki dunia kerja juga dapat tercapai. Selain dari antusiasme peserta dalam mengikuti kegiatan ini, pemahaman peserta juga dinilai dari pengisian angket pre-test dan post-test kegiatan. Setelah dianalisis, terdapat peningkatan pengetahuan peserta mengenai literasi keuangan dan personal branding dari sebelum materi diberikan sampai setelah materi diberikan. Selain itu, faktor yang mendukung kegiatan ini adalah adanya sikap kooperatif dan informatif yang ditunjukkan oleh pihak SMK PGRI 1 Kedondong. Pihak sekolah menerima Tim PKM dengan sangat antusias dan mendukung penuh kegiatan ini. Rencana selanjutnya yang dapat dilakukan oleh Tim PKM adalah dengan menjaga hubungan baik dengan mitra sekolah binaan sehingga jika terdapat kegiatan serupa, dapat bekerjasama kembali dengan baik.

\section{UCAPAN TERIMA KASIH}

Ucapan terima kasih kami sampaikan kepada Universitas Teknokrat Indonesia yang telah memfasilitasi kegiatan ini melalui hibah Pengabdian Kepada Masyarakat Sekolah Binaan. Selain itu, kami juga mengucapkan terima kasih kepada pihak SMK PGRI 1 Kedondong yang telah memberikan kesempatan bagi Tim PKM untuk melaksanakan kegiatan ini.

\section{REFERENSI/DAFTAR PUSTAKA}

Deckers, E., dan Lacy, K. (2011). Branding: How to Use Social Media to Invent or Reinvent Yourself. USA: Pearson Education.

Jogiyanto, H. (2017). Teori Portofolio dan Analisis Investasi. Yogyakarta: BPFE-YOGYAKARTA.

Lusardi, A. (2019). Financial literacy and the need for financial education: evidence and implications. Swiss Journal of Economics and Statistics, 155(1), 1-8.

Riset KIC-Kredivo: Rata-rata Orang RI Belanja Online 20 Kali pada 2019. (2020). Diakses pada 11 Januari 2020 melalui https://katadata.co.id

Ahdan, S., \& Sari, P. I. (2020). PENGEMBANGAN APLIKASI WEB UNTUK SIMULASI SIMPAN PINJAM (STUDI KASUS: LEMBAGA KEUANGAN SYARIAH BMT L-RISMA. Jurnal Tekno Kompak, 14(1), 33-40.

Setiawansyah, S., Sulistiani, H., \& Saputra, V. H. (2020). Penerapan Codeigniter Dalam Pengembangan Sistem Pembelajaran Dalam Jaringan Di SMK 7 Bandar Lampung. Jurnal CoreIT: Jurnal Hasil Penelitian Ilmu Komputer Dan Teknologi Informasi, 6(2), 89-95.

Sulistiani, H., Yuliani, A., \& Hamidy, F. (2021). Perancangan Sistem Informasi Akuntansi Upah Lembur Karyawan Menggunakan Extreme Programming. Technomedia Journal, 6(01 Agustus).

Surahman, A., Octaniansyah, A. F., \& Darwis, D. (2020). Teknologi Web Crawler Sebagai Alat Pengembangan Market Segmentasi Untuk Mencapai Keunggulan Bersaing Pada E-Marketplace. Jurnal Komputer Dan Informatika, 15(1), 118-126.

Suryono, R. R., Purwandari, B., \& Budi, I. (2019). Peer to peer (P2P) lending problems and potential solutions: A systematic literature review. Procedia Computer Science, 161, 204-214. 